\title{
Doações de Terras Públicas e Questões Urbano-Religiosas: Um Estudo de Caso na "Capital Da Fé" - Juazeiro do Norte - CE
}

Donations of Public Lands and Urban and Religious Issues: A Case Study in the "Capital Da Fé" - Juazeiro do Norte - CE

Geovane Gesteira Sales Torres [a] [D], Diego Coelho do Nascimento [a] [D]

[a] Universidade Federal do Cariri (UFCA), Laboratório de Estudos Urbanos, Sustentabilidade e Políticas Públicas (Laurbs), Juazeiro do Norte, CE, Brasil

Como citar: Torres, G. G. S, \& Nascimento, D. C. (2021). Doações de Terras Públicas e Questões UrbanoReligiosas: Um Estudo de Caso na "Capital da Fé" - Juazeiro do Norte - CE. urbe. Revista Brasileira de Gestão Urbana, v. 13, e20200167. https://doi.org/10.1590/2175-3369.013.e20200167

\section{Resumo}

Refletir epistemologicamente sobre o espaço urbano nos direciona a contemplar a cidade como algo além de ruas, parques e moradias. Nesse viés, seguindo correntes urbanísticas críticas, devem-se considerar as relações de poder enquanto artefatos substanciais à ocupação/divisão do espaço urbano público e privado, bem como ao direito à cidade. Berço no qual repousam argumentos sinalizadores de assimetrias provenientes de questões de ordem subjetiva, como a religião. Assim, faz-se necessário pensar a relação entre o espaço público e religião. Não obstante, a presente pesquisa exploratória, de natureza qualitativa, versa analisar as doações próprias da municipalidade de Juazeiro do Norte - CE a organizações/instituições/finalidades religiosas, entre os anos 2000 a 2019. Para tal, adotou-se, como método de coleta de dados, uma pesquisa documental na legislação ordinária ambiental do município e, para a sistematização e apresentação das informações, incorporaram-se métodos/técnicas de estatística descritiva. Diagnosticou-se expressiva parcela de doações próprias da municipalidade de Juazeiro do Norte a organizações/instituições católicas e, em sobreposição, evangélicas. Isso não se projeta a religiões socialmente marginalizadas, tais como as de matrizes africanas, afro-brasileiras, espíritas e indígenas. É uma realidade incongruente às prerrogativas constitucionais brasileiras, sobretudo, em virtude dos seus fins meramente religiosos e não equitativos em relação a doutrinas não cristãs e não hegemônicas.

Palavras-chave: Espaço público. Planejamento Urbano. Laicidade. Cidades. Religião.

\section{Abstract}

Reflecting epistemologically on urban space directs us to contemplate the city as something other than streets, parks and houses. In this bias, following critical urban currents, power relations must be considered as substantial artifacts for the occupation / division of public and private urban space, as well as for the right to the city. Cradle in which there are arguments that signal asymmetries arising from subjective 
issues, such as religion. Thus, it is necessary to think about the relationship between public space and religion. Nevertheless, the present exploratory research, of a qualitative nature, deals with analyzing donations from the municipality of Juazeiro do Norte - CE to religious organizations / institutions, between the years 2000 to 2019. For this, it was adopted, as a method of collecting data, a documentary research in the ordinary environmental legislation of the municipality and for the systematization and presentation of information, methods / techniques of descriptive statistics were incorporated. A significant portion of donations from the municipality of Juazeiro do Norte was diagnosed to Catholic organizations / institutions and, in overlap, evangelical ones. What is not projected to socially marginalized religions, such as those of African, Afro-Brazilian, spiritist and indigenous origins. Incongruent reality to Brazilian constitutional prerogatives, above all, due to their purely religious and unequal ends in relation to non-Christian and nonhegemonic doctrines.

Keywords: Public place. Urban planning. Secularity. Cities. Religion.

\section{Introdução}

As discussões tocantes ao ambiente urbano ocupam, paulatinamente, espaços em diversas esferas sociais. Suas variações abarcam aspectos que vão do planejamento urbano às sociabilidades dos ocupantes das cidades, apresentando, então, distinções quanto aos métodos e orientações epistemológicas empregadas. É algo que se desnuda como urgente ao Brasil, considerando-se suas variações em relação à redução da taxa de natalidade, proeminente aumento da expectativa de vida e hipertrofia da tendência à continuidade da urbanização em que sua população cresce em demasia - gerando o fenômeno de "inchaço urbano" - e em desproporção à média da população total (Grostein, 2001).

Nesse direcionamento, Maricato (2015) indica que a academia desempenha um papel salutar no que tange à exposição das cidades brasileiras tal como elas são. Sendo assim, evidencia as potencialidades, experiências benfazejas, mas também as contradições e mazelas socioambientais que permeiam os centros urbanos brasileiros.

Essa "exposição" conclamada por Maricato (2015) se faz necessária para a manutenção do sistema democrático, considerando-se as inúmeras antinomias que marcam a dinâmica das cidades, sobretudo as localizadas no capitalismo periférico, que corroboram para a exclusão própria do sistema hegemônico, em decorrência de suas tendências comportamentais, produtor de privações e assimetrias em termos de acesso a bens e serviços fundamentais. Salienta-se que, para além de razões econômicas, outros fatores se projetam na produção de desigualdades relativas ao direito à cidade enquanto garantia presente na dimensão pública —, tal como advoga Giumbelli (2008), ao pensar a relação entre o espaço público e religião.

Nesse hiato, a constitucionalidade brasileira, em seus dispositivos presentes na carta magna (Brasil, 1988), preceitua a liberdade religiosa entre os cidadãos brasileiros. Tal direito se assenta no Art. $5^{\circ}$, garantidor da igualdade legal entre os sujeitos, inciso VI, em que se expressa: "é inviolável a liberdade de consciência e de crença, sendo assegurado o livre exercício dos cultos religiosos e garantida, na forma da lei, a proteção aos locais de culto e a suas liturgias" (Brasil, 1988).

Tratar das doações públicas de terrenos/patrimônios materiais no espaço urbano brasileiro converge a reflexões históricas e jurídicas remotas, observando-se que políticas nesse escopo se imprimem desde o período colonial. Contudo, é apenas com a promulgação da Constituição Federal de 1988 que a República Federativa do Brasil positiva juridicamente a função social da propriedade urbana, contrastando às tendências anteriores marcadas por intensos privilégios e desigualdades. Em seu Art. 182, a carga magna expressa que as esferas municipais devem executar o seu desenvolvimento urbano guiadas pelos objetivos da função social da cidade e bem-estar dos cidadãos, itinerário que deverá ser estrategicamente direcionado pelos Planos Diretores. Estes desempenham o 
papel central de prever a função social urbana, por meio da sua previsão para a ordenação da cidade (Brasil, 1988).

Desse modo, a presente pesquisa exploratória versa analisar as doações de terrenos próprios da municipalidade de Juazeiro do Norte - CE a organizações/instituições/destinações de caráter religioso, entre os anos 2000 e 2019. Para tal, adotou-se, como método de coleta de dados, uma pesquisa documental na legislação ordinária ambiental e urbanística do município no recorte temporal ora exposto. A discussão dos resultados considerou reflexões epistemológicas e dados oficiais que propiciam observar as confluências e incongruências entre as doações aqui tratadas, epistemes e dispositivos jurídicos tocantes à constitucionalidade, à ciência da religião e ao espaço público.

De tal forma, o trabalho em questão se apresenta relevante por sua propriedade indutiva em realizar um estudo de caso sobre a experiência do município de Juazeiro do Norte em relação às doações próprias da municipalidade a organizações religiosas que nos proporciona notar conflitos de motivações na perseguição ao interesse público, além dos impactos socioambientais gerados por tais atos legislativos.

Ao longo do presente artigo trabalhar-se-ão discussões político-conceituais em torno de noções de cidade, relações de poder, esferas pública e privada, laicidade do Estado, além de apresentar considerações históricas e contemporâneas em relação ao município de Juazeiro do Norte - CE.

\section{O público e o religioso no Brasil}

Arendt (2007) contempla a esfera pública como uma seara que abarca múltiplas perspectivas e aspectos por meio dos quais o mundo comum vem à tona, tendo em conta que o ato de ser visto/ouvido é importante porque os ouvintes e ventes assim o fazem de formas distintas. Gera-se, então, o chamado mundo-comum, pois interesses seriam compartilhados no intento de gozar da sociabilidade que apenas o espaço público pode ofertar.

Assim, a diversidade de visões constitui o mundo-comum, contribuindo, portanto, para a emersão do mundo, em que este transcende a vida privada por meio da experiência da pluralidade, pois, mesmo o mundo familiar não substitui a conjuntura resultante das múltiplas facetas dos objetos e suas inúmeras interpretações (Arendt, 2007). Nota-se, contudo, que na modernidade os limites entre os âmbitos público e privado se confundem de forma latente, fato que resultará em graves problemáticas no modus operandi do Estado moderno.

Antunes (2004) destaca que Hanna Arendt defende que a confusão entre os âmbitos público e privado decorre da visão social de enxergar a política como meio de regulação da vida privada. Assim, o Estado amiúde regula a vida privada por meio de uma administração doméstica coletiva.

Nessa lógica, consoante Giumbelli (2008), pensar a existência de interesses religiosos no espaço público é convidativo a contemplar que a sua presença está correlata, apesar ou em decorrência, dos aparelhos/dispositivos estatais. Nesse sentido, a secularização ${ }^{1}$ - laicidade - no Brasil tem a sua gênese com a instauração da república, no século XIX, quando se rompe com a Igreja Católica que, até então, detinha o gozo de religião oficial da nação. Todavia, a dinâmica e a cultura política do país fizeram com que a Igreja Católica influenciasse grandemente na definição do novo regime de relações entre o Estado e religiões no advento republicano. Isso se consubstanciou no âmago de dispositivos legais como os presentes na Constituição de 1934, que em seu bojo preconizava o ensino religioso em instituições formais, a validade civil do casamento religioso, além de coproduções entre o poder público e instituições religiosas (Giumbelli, 2008), servindo, assim, apenas para positivar um fato já existente desde o período de colonização do Brasil, quando as influências religiosas lusitanas serviram

\footnotetext{
${ }^{1}$ A secularização consiste em fluxos distintos relacionados aos variados fenômenos sociais/políticos e dispositivos legais nos quais se faz presente a redução da atuação de organizações, práticas e ideologias de cunho religioso (Cf. Mariano, 2011).
} 
para edificar uma cultura político-institucional intimamente guiada por princípios e lógicas cristãs católicas (Holanda, 1995).

Outrossim, Giumbelli (2008) afirma que o Código Civil de 1917 fundamentou juridicamente os coletivos religiosos no Brasil, implicando o seu reconhecimento e de muitos de seus atos, sem expressar nítidas restrições. Todavia, estas existiam, já que o ordenamento jurídico em vigor pressupunha o tolhimento de ações religiosas denominadas "ilícitas" e "imorais", projetando-se, sobretudo, nas religiões entendidas como mediúnicas - contemplando religiões de matrizes africanas, afro-brasileiras, espíritas kardecistas, práticas de curandeirismo, xamanismo etc. (Giumbelli, 2008).

Contemporaneamente, com a instituição da República Federativa do Brasil, a partir da Constituição Federal de 1988, a laicidade estatal é um aparato previsto na organização do Estado Brasileiro. Portanto, o Art. 19 da Constituição da República Federativa do Brasil (1988) veda à União, Estados, Municípios e Distrito Federal: "I - estabelecer cultos religiosos ou igrejas, subvencioná-los, embaraçar-lhes o funcionamento ou manter com eles ou seus representantes, relações de dependência ou aliança, ressalvada, na forma da lei, a colaboração de interesse público" (Brasil, 1988).

\section{A ocupação do espaço urbano e as relações religiosas}

Lefebvre (1972) destaca que a cidade reflete a essência da sociedade. Esta, em seus moldes capitalistas, marca-se por intensas desigualdades sociais condicionadas, consoante a perspectiva marxista de Lefebvre (1972), por questões de ordem econômica, algo que refletirá na realidade da "urbe". Não obstante, Corrêa (1989) exclama que o espaço urbano é subdivido em zonas qualificadas por seu uso e conteúdo social. Desse modo, o espaço urbano é entendido por Corrêa (1989) como uma complexa justaposição de terras que se marcam por fragmentações e articulações produzidas historicamente, numa visão confluente ao conceito de cidade justaposto por Lefebvre (1972, p. 89):

Que é então a cidade? A exemplo da terra em que se apoia, é um meio ambiente, um intermediário, uma mediação, um meio [...] A cidade percorre assim os modos de produção, processo que se inicia logo que a comuna urbana substitui a comunidade (tribal ou agrária) ligada de perto à terra. A cidade torna-se, assim, o grande laboratório das forças sociais.

As desigualdades na produção e ocupação do espaço urbano indicadas por Lefebvre (1972) se encontram na visão de Corrêa (1989) quando este sinaliza que, além das zonas definidas por seus usos, as áreas residenciais tendem a se segregar em virtude das complexas classes sociais. Mesmo impregnadas pelo reducionismo infraestrutural marxista, as visões de Lefebvre (1972) e Corrêa (1989) põem a nu a propriedade essencialmente política da cidade.

Cabe-se destacar que a cidade não apenas reflete a sociedade em que se encontra, mas, possui o poder de influenciar os comportamentos e instituições sociais. Assim, o espaço urbano se fragmenta por seus usos e estratificações sociais; articula-se para o atendimento dos interesses dominantes; reflete as relações sociais nas quais se insere, mas também produz as relações e instituições sociais (Corrêa, 1989). Concentrando pessoas, meios de produção, necessidades, fruições e capital, enquanto sujeito histórico, a cidade necessita ser administrada, concedendo, então, espaço ao papel ideal do Estado em retirar parte da mais valia e a destinar a serviços públicos essenciais (Lefebvre, 1972). Corrêa (1989) advoga que além do ator estatal, outros atuam na produção da cidade, os quais são: I) Proprietários dos meios de produção; II) Proprietários fundiários; III) Promotores imobiliários e IV) Grupos sociais excluídos.

Visto isso, concebe-se que as relações de poder desenvolvidas nas cidades não são inertes, então, os atores mencionados por Corrêa (1989) atuam dialeticamente e conflituosamente por meio de instrumentos que almejam a interferência na produção da cidade. Dessa maneira, a realidade urbana não é cristalizada, mas dinâmica e assimétrica. Isso implica dizer que elites tendem a gozar das 
benesses urbanas à revelia dos grupos minoritários - porém, estes, amiúde, resistem a tais situações desfavoráveis, fenômeno nitidamente exposto nas análises europeias realizadas por Lefebvre (1972).

Nesse esteio, deve-se pontuar que tais elites e grupos minoritários não são produzidos socialmente apenas em decorrência do aspecto econômico - infraestrutural - , mas também se fazem por meio de questões de ordem subjetiva - observação que pouco se fez/faz presente nos estudos urbanos, incluindo-se os de Lefebvre (1972) e Corrêa (1989). Realidade convidativa a evocar a visão decolonial de Chueca (2019), a qual afirma que a economia política da cidade também deve se voltar à complexidade das relações de poder que envolvem questões como o patriarcado e racismo, convergindo à visão de Santos (2013, p. 58) de que: "Nos países periféricos [...] as formas de opressão e dominação assentes na raça, na etnia, na religião e no sexo afirmam-se pelo menos tão importantes quanto as assentes na classe".

Assim, contempla-se a cidade como um meio espacial e simbólico onde as relações de poder se incidem e, por conseguinte, tem a sua ocupação e dinâmica marcadas por assimetrias. Desse modo, partindo-se do pressuposto de que questões de ordem subjetiva, como a religião, são historicamente hegemonizadas socialmente, as tendências comportamentais - tal qual a religião - passarão a influenciar na distribuição e acesso ao direito à cidade.

Nesse viés, a historiografia nos aponta que em virtude do processo da colonização brasileira, intensamente marcado pela incorporação de modelos institucionais, políticos e culturais lusitanos, a religião católica terminou por influenciar grandemente na formação da nacionalidade (Holanda, 1995), fato que, evidentemente, marcou os fluxos assimétricos no tocante à ocupação do solo urbano. Afinal, enquanto templos católicos se sediavam nos centros estratégicos dos polos urbanos, espaços sagrados de religiões de matrizes africanas eram - são - situados em periferias e, amiúde, vítimas de inúmeras formas de violação. A fim de exemplificação, Lühning (1996) conclui, por meio de análises de publicações jornalísticas entre os anos de 1919 a 1942, que eram inúmeras e truculentas as chamadas "batidas" - repressões - policiais aos terreiros de candomblé na Bahia. Essas situações, ainda consoante Lühning (1996), refletiam a intolerância não apenas dos órgãos de policiamento, mas da mídia local enquanto instituição representante da opinião pública da elite.

Então, ao se contemplar a realidade urbana baiana, aufere-se uma problemática não restrita a este território, mas, compartilhada historicamente por inúmeros centros urbanos no Brasil. Pois, conforme destaca Karnal (2017), o mito da democracia racial e da cordialidade brasileira é nitidamente desconstruído ao se enxergar um arranjo nacional historicamente edificado à luz de uma cultura violenta e intolerante - algo que se faz necessário para se pensar a cidade e o direito a ela.

\section{O território da pesquisa}

Situada na Região Metropolitana do Cariri - RM Cariri² ${ }^{2}$ localizada a $528 \mathrm{~km}$ da capital Fortaleza e equidistante de todas as capitais nordestinas (IGBE, 2010), para além de índices aferidores de desenvolvimento, Juazeiro do Norte, vulgo "capital da fé", comporta fenômenos socioculturais nem sempre passíveis à quantificação, tais como as romarias católicas impulsionadas pelo devocionismo popular ao Padre Cícero Romão Batista.

Segundo Cordeiro (2010), Juazeiro do Norte surge aos arredores de uma capela em homenagem à Nossa Senhora das Dores, fundada em 1827. 0 município teve a sua formação demográfica marcada por migrantes sertanejos da seca e em decorrência de motivos religiosos circunscritos à figura político-carismática do Padre Cícero. Muitos desses sujeitos chegavam à cidade em tempos de romarias, pois "O imaginário que instituiu a centralidade de Juazeiro do Norte, não tardou a

${ }^{2}$ A RM Cariri, criada pela Lei Complementar no 78, 26 de junho de 2009, é composta pelas cidades: Juazeiro do Norte, Crato, Barbalha, Jardim, Missão Velha, Caririaçu, Farias Brito, Nova Olinda e Santana do Cariri. 
constituir-se principal motivador para migrações em massa para o município" (Cordeiro, 2010, p. 120). Assim, o elo motriz entre o território e os migrantes romeiros consistia na esperança expectativas subjetivas - quanto às promessas transcendentais calcadas na dualidade oração/trabalho.

De sua independência, em 1911, aos dias atuais, a cidade aumentou inescrupulosamente a sua demografia, comércio e edificações - regularizadas ou não. Ademais, na contemporaneidade Juazeiro do Norte é marcada por ações empresariais, estatais e religiosas que fomentam a figura do patriarca do município, sobretudo no que tange à gestão das romarias ${ }^{3}$. Estas passaram a ser fluxos do turismo religioso, sendo um dos pilares fundamentais para o desenvolvimento econômico local (Cordeiro, 2010).

Em Juazeiro do Norte, o catolicismo popular se faz presente de forma intensa, configurando-se como um efeito da resistência de grupos marginalizados (negros e indígenas) à interposição religiosa católica. Assim, de forma distinta ao catolicismo romano, o catolicismo popular na cidade se mostra como uma ressignificação de ritos, símbolos, signos e crenças coloniais intuindo torná-las inteligíveis por meio de sistemas simbólicos contextualizados. As manifestações religiosas decorrentes de tais fenômenos no sertão brasileiro se produzem mediante choques culturais das linguagens e instituições europeias com o hibridismo étnico regional de grupos sociais subalternizados, originando fenômenos como devoções a santos populares - não canonizados e/ou não católicos - como o Padre Cícero, grupos de tradição e celebrações populares como as renovações ao sagrado coração de Jesus e ao imaculado coração de Maria (Oliveira, 2019).

Nesse contexto, salienta-se que a cidade em discussão possui uma população estimada em 274.207 pessoas no ano de 2019, portando, em 2010, uma densidade demográfica de $1.004,45$ habitantes por $\mathrm{km}^{2}$, considerada demasiadamente alta (IBGE, 2010).

Portanto, contempla-se uma realidade marcada por problemas públicos urbanos. Nesse sentido, o Plano Diretor de Juazeiro do Norte (2000) agiria idealmente para direcionar e promover o desenvolvimento urbano e solucionar tais percalços, tal como preceitua o Art. 182 da carta magna (Brasil, 1988). Todavia, o Plano Diretor da cidade em voga se encontra obsoleto, pois, desde a sua formulação, não foram realizadas atualizações, circunstância que faz com que a atual realidade urbana, e os seus problemas, não sejam de fato previstos juridicamente, gerando um caos nos processos de ocupação e uso do solo (Rodrigues, 2019).

Devido a essa defasagem no Plano Diretor do município, doações de terrenos públicos são realizadas sem critérios bem definidos e condizentes à constitucionalidade brasileira e ao Estatuto da Cidade (logo, visando à função social da cidade e à qualidade de vida dos cidadãos). Isso se constatará no presente artigo, em que se apresentarão dados e análises indicadoras da escassez de objetividade e laicidade nos atos que culminam nas doações próprias da municipalidade de Juazeiro do Norte.

\section{Desenvolvimento}

A pesquisa em questão adota como objeto de observação científica as doações de terrenos próprios da municipalidade de Juazeiro do Norte - CE a organizações/instituições/finalidades religiosas, entre os anos de 2000 a 2019, enquanto parte integrante da legislação ordinária urbanística e ambiental municipal edificada por decisões políticas protagonizadas pelos poderes públicos executivo e legislativo da cidade, apresentando inúmeras finalidades condizentes a interpretações sobre o interesse público da ocupação do solo urbano.

\footnotetext{
${ }^{3}$ As romarias em Juazeiro do Norte são fenômenos religiosos do catolicismo popular centralizados na devoção de fiéis de várias partes do nordeste, e outras regiões do país, ao Padre Cícero Romão Batista. As três maiores romarias são: I) Festividade de Nossa Senhora das Candeias (2 de fevereiro); II) De finados (de 29 de outubro a 02 de novembro); III) Comemoração do aniversário natalício do Padre Cícero (24 de março).
} 
Sua classificação em relação aos seus fins a delineia como uma pesquisa exploratória, pois objetiva travar discussões político-conceituais sobre aspectos teóricos e jurídicos em interface com os dados empíricos obtidos no presente estudo de caso. Segundo Prodanov \& Freitas (2013), a pesquisa exploratória condiz a investigações em fases preliminares, sem tantos resultados antecedentes, cuja finalidade é ofertar informações sobre o objeto observado, guiar a delimitação dos objetivos e a geração de hipóteses e até mesmo desvendar novas perspectivas para o tema. Essa matriz se configura, amiúde, em pesquisas bibliográficas e estudos de caso e possui um planejamento flexível.

Já em relação aos seus meios, o trabalho se configura como uma pesquisa documental, pois adota fontes de informações que ainda não receberam tratamento analítico, já que se trata de legislações, o que permite aos pesquisadores maior direcionamento dos dados aos objetivos do trabalho (Gil, 2008).

O tratamento dos dados seguiu uma natureza qualitativa, pois, ao contemplar o caráter religioso/laico das organizações/instituições beneficiadas, ou suas finalidades, com as doações dos terrenos próprios da municipalidade, bem como os anos de tais atos públicos e suas destinações, foi possível empreender fluxos subjetivos de interpretação, com base em teorias político-conceituais, além de partir de representações estatísticas descritivas quanto à proporção numérica de cada uma das categorias criadas e discutidas qualitativamente (Prodanov \& Freitas, 2013).

Em relação ao método de coleta e análise dos dados, realizou-se uma leitura flutuante no site da Prefeitura Municipal de Juazeiro do Norte, em que consta a legislação munícipe, momento quando se identificaram as leis ordinárias tocantes às distintas finalidades urbanas e ambientais: 1) Permutas; 2) Plano Diretor Municipal; 3) Prorrogação de leis anteriores; 4) Revogação de leis anteriores; 5) Permissão ao uso de bem público; 6) Habitação; 7) Desafetação; 8) Desapropriação; 9) Áreas especiais de interesse social e 10) Doações. Assim, das 253 leis ordinárias relacionadas às doações, entre os anos 2000 a 2019, delimitaram-se categorias específicas quanto às doações em benefício de organizações/instituições/destinos de caráter religioso.

\section{Considerações Estatísticas}

O presente artigo formulou variáveis qualitativas - de tipo nominal — para análise do fenômeno estudado. Então, utilizaram-se técnicas de estatística descritiva para o processo de quantificação das variáveis pertinentes às categorias formuladas no universo estatístico investigado - 20 doações às organizações/instituições/finalidades religiosas. A coleta dos dados se deu de forma direta na legislação ordinária ambiental/urbanística do município de Juazeiro do Norte. Calculou-se a distribuição dos dados absolutos em classes pelas frequências: absoluta, relativa e percentual. A primeira corresponde ao valor de ocorrências de cada classe. Já a segunda se configura pelo quociente tocante ao quantitativo de dadas ocorrências em relação ao total, sendo representada pela fórmula: $f r=f / \Sigma f$. Enfim, a frequência percentual implica no valor percentual de dada classe em relação ao total de frequências, representada pela fórmula: $f \%=100 \mathrm{fr}$ (Morettin, 2010).

\section{Resultados e Discussão}

Mediante a análise desenvolvida no recorte temporal pesquisado, aferiu-se que foram realizadas 253 doações próprias da municipalidade de Juazeiro do Norte - CE, dentre as quais se encontram as finalidades: indústria; empreendimentos; público e social. No seio desta, repousam as destinações a organizações/instituições religiosas. Tal como se observa na Tabela 1, em números absolutos, foram realizadas 20 doações a organizações/instituições religiosas de 2000 a 2019, representando, percentualmente, $7,93 \%$ em relação ao total. 
Tabela 1 - Destino das doações em relação ao caráter religioso dos beneficiados/finalidades

\begin{tabular}{lll}
\hline Caráter laico/religioso dos beneficiados das doações & $\mathbf{N}^{\circ}$ de doações & Percentual de doações (\%) \\
\hline Doações a organizações/instituições/finalidades religiosas & 20 & $7,93 \%$ \\
Doações a organizações/instituições não religiosas & 233 & $92,46 \%$ \\
Total & 253 & $100 \%$ \\
\hline
\end{tabular}

Fonte: Produzido pelos autores com dados da pesquisa.

O valor majoritário das doações públicas contemplou instituições católicas, bem como se nota na Tabela 2. Contudo, na legislação municipal não constam as relações das solicitações das doações públicas, então, tais informações não podem ser aferidas na fonte de dados incorporada na presente pesquisa. Entretanto, resguardados pela lei federal $n^{\circ} 12.527$ (Brasil, 2011), solicitou-se a relação de instituições/denominações religiosas solicitantes de doações nessa modalidade entre os anos de 2000 a 2019. Assim, encaminharam-se pedidos ao Gabinete do Prefeito, à ouvidoria e à câmara de vereadores de Juazeiro do Norte. Porém, até a data de submissão da presente investigação, as solicitações em voga não foram atendidas.

Tabela 2 - Lista das organizações e classificações religiosas beneficiadas.

\begin{tabular}{ll}
\hline Religião & Organização/instituição \\
\hline Católica Apostólica Romana & Diocese do Crato \\
& Sociedade Apostólica das Servas de Jesus Cristo \\
& Associação Jesus é o Senhor e Imaculada Nossa Mãe \\
& Comunidade água viva \\
& Associação Mãe Santíssima \\
& Irmandade de Santa Luzia \\
& Associação Maria Mãe da Vida \\
& Comunidade de Evangelização Fonte de Vida \\
& Associação Comunitária do Bairro Campo Alegre \\
& Associação de Apoio aos Necessitados \\
& Fundação Terra \\
& Associação Filhos Amados do Céu \\
Igreja Evangélica Assembleia de Deus & Igreja Pentecostal Caminho da Vida \\
Evangélica & Associação dos Reikianos do Cariri \\
\hline
\end{tabular}

Fonte: Produzido pelos autores com dados da pesquisa.

Como exposto na Tabela 3 e Figura 1, observa-se, temporalmente, que, durante os cinco primeiros anos analisados, o ano de 2003 assume o maior quantitativo de doações a instituições/destinações religiosas - mandato de Carlos Alberto da Cruz (Partido de Frente Liberal). Já de 2005 a 2009, houve o período com maiores percentuais - 55\% do total de doações a organizações/instituições religiosas, assumindo o ano de 2008 a maior parcela (20\%) — mandato de Raimundo Antônio Macêdo (Partido do Movimento Democrático Brasileiro - PMDB), sendo seguido pelo ano de 2006 (15\%) — mandato de Raimundo Antônio Macêdo (PMDB). Entre 2010 e 2014, houve um período com um dos menores fluxos de doações (10\%) aos entes aqui referidos — mandato de Manoel Raimundo de Santana Neto (Partido dos Trabalhadores) e, nos últimos dois anos, mandato de Raimundo Antônio Macêdo (PMDB). Já os anos de 2015 e 2016 também apresentam um baixo percentual de ações (10\%), equitativo ao de 2010 a 2014, todavia, com dois anos a menos na quantificação - mandato de Raimundo Antônio Macêdo (PMDB). Já de 2017 a 2019, mandato de Arnon Bezerra (Partido Trabalhista Brasileiro), houve $10 \%$ das doações, percentual considerado baixo. 
Tabela 3 - Doações a organizações/fins religiosos entre 2000 e 2017

\begin{tabular}{lll}
\hline Ano de doação & $\mathbf{N}^{\circ}$ Absoluto & Percentuais \\
\hline 2000 & 0 & $0 \%$ \\
2001 & 0 & $0 \%$ \\
2002 & 0 & $0 \%$ \\
2003 & 3 & $15 \%$ \\
2004 & 1 & $5 \%$ \\
2005 & 0 & $0 \%$ \\
2006 & 3 & $15 \%$ \\
2007 & 2 & $10 \%$ \\
2008 & 4 & $20 \%$ \\
2009 & 2 & $10 \%$ \\
2010 & 1 & $5 \%$ \\
2011 & 1 & $5 \%$ \\
2012 & 0 & $0 \%$ \\
2013 & 0 & $0 \%$ \\
2014 & 0 & $0 \%$ \\
2015 & 1 & $5 \%$ \\
2016 & 0 & $0 \%$ \\
2017 & 1 & $5 \%$ \\
2018 & 0 & $0 \%$ \\
2019 & 1 & $5 \%$ \\
\hline Total & 20 & $00 \%$ \\
\hline
\end{tabular}

Fonte: Produzido pelos autores com dados da pesquisa.

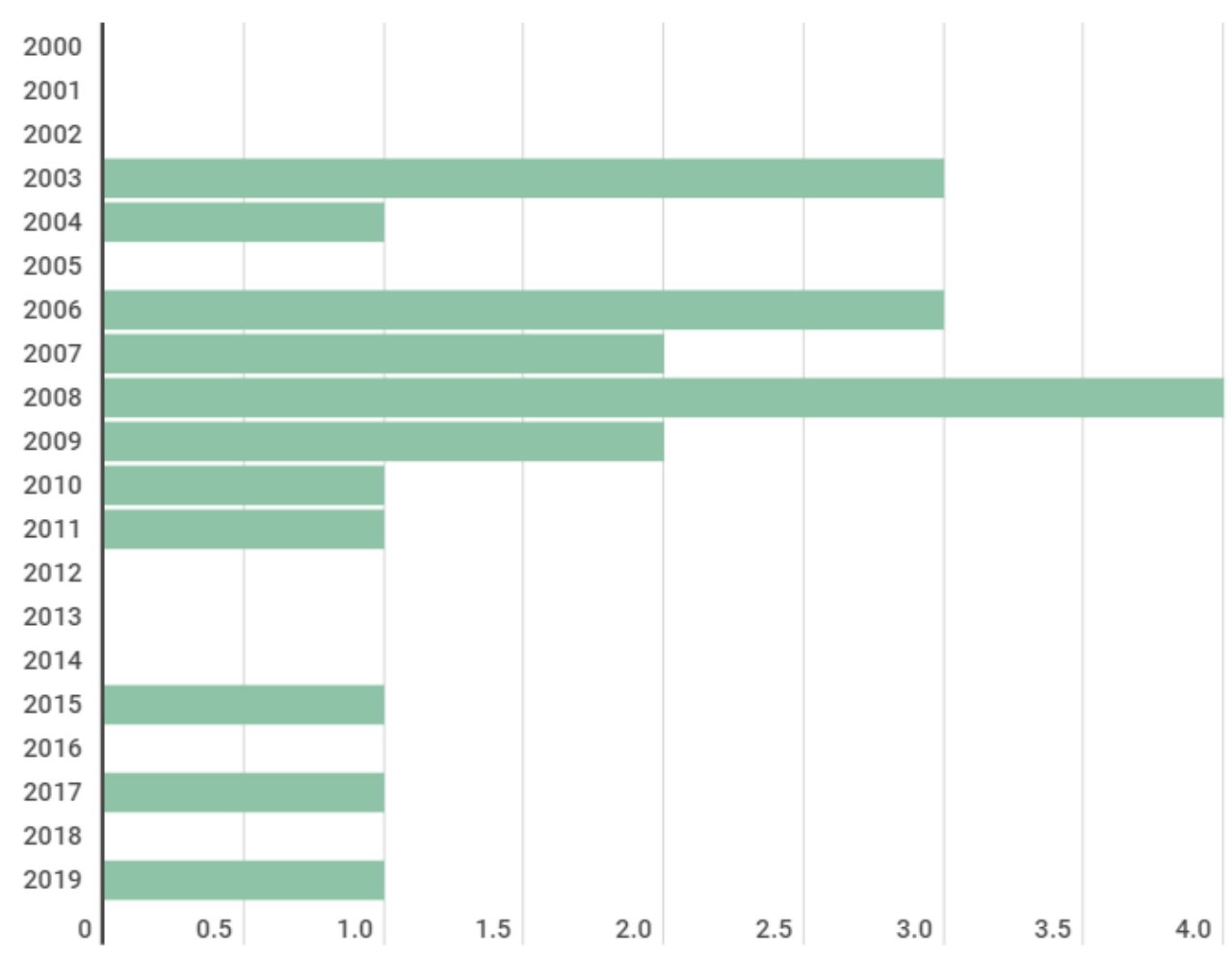

Figura 1 - Números absolutos de doações a organizações/fins religiosos entre 2000 e 2019. Fonte: Produzido pelos autores com dados da pesquisa. 
No tocante às matrizes religiosas das organizações/instituições beneficiadas com as doações, nota-se que, no período investigado, $85 \%$ foram católicas, sendo seguidas por igrejas evangélicas 4 (10\%) e, em último plano, organizações de Reiki ${ }^{5}$ (5\%). As instituições beneficiadas são majoritariamente católicas, porém, dentre elas, a maior contemplada com tais atos foi a Diocese de Crato (30\%), ao passo que as demais doações incluem apenas duas igrejas evangélicas (Igreja Evangélica Assembleia de Deus e Igreja Pentecostal Caminho da Vida) e uma organização reikiana (Associação dos Reikianos do Cariri). Assim, ao se contemplar a formação histórico-cultural de Juazeiro do Norte, bem como exposto por Cordeiro (2010), vislumbra-se uma conjuntura políticoinstitucional em que a Igreja Católica exerce bastante influência e, assim, goza de benesses advindas da esfera pública local. 0 fenômeno não ocorre isoladamente; observa-se que, mesmo com o advento da secularização no Brasil, a Igreja Católica assumiu um papel singular na constituição do Estado Brasileiro (Giumbelli, 2008).

Destaca-se que Juazeiro do Norte é um território predominantemente católico, em termos demográficos e culturais, justificando as dificuldades de percepção em relação a outras denominações religiosas na cidade (Diniz, 2013). Todavia, tal como se nota na Tabela 4, a denominação religiosa mais contemplada com as doações, após a Igreja Católica, foi a evangélica. Logo, notar a diversidade religiosa na "capital da fé" é algo relevante, a julgar pela existência, consoante Diniz (2013), de mais de 70 igrejas evangélicas na localidade entre os anos de 2010 a 2011. Confluindo ao constatado por Giumbelli (2008) de que a inserção das igrejas evangélicas, sobretudo no campo político, vem sendo um proeminente fenômeno nas últimas décadas no Brasil, convergindo a consideráveis ocupações em espaços públicos e parcerias entre igrejas e esfera pública, algo projetado nas doações aqui estudadas.

Tabela 4 - Distribuição das doações por religiões

\begin{tabular}{lll}
\hline Religiōes & $\mathbf{N}^{\circ}$ de organizações & Percentuais das religiões (\%) \\
\hline Católica & 17 & $85 \%$ \\
Evangélica & 2 & $10 \%$ \\
Reiki & 1 & $5 \%$ \\
\hline Total & 20 & $100 \%$ \\
\hline
\end{tabular}

Fonte: Produzido pelos autores com dados da pesquisa.

Entretanto, um questionamento se desnuda: apenas ramificações doutrinárias cristãs se assentam no território investigado? Notoriamente, não. A considerar o hibridismo cultural que circunda a formação da brasilidade, religiões de matrizes africanas e afro-brasileiras, bem como indígenas e de origens europeias - ex: espiritismo kardecista - se fazem presentes nas artérias urbanas do espaço pesquisado. Segundo o IBGE (2010), a maioria dos citadinos de Juazeiro do Norte professam a fé Católica Apostólica Romana, cerca de 218.944 pessoas. Porém, valores expressivos de juazeirenses adotam outras opções religiosas, tal como se nota na Figura 2. Mesmo com a caducância de tais dados, tendo em vista que estão obsoletos frente à realidade urbana municipal, a curiosidade magna versa sobre a pouca ou não representação de tais opções religiosas com doações próprias da municipalidade.

\footnotetext{
${ }^{4}$ No Brasil, o uso do termo evangélico remonta uma diversidade de denominações religiosas advindas da Reforma Protestante (século XVI), gerando inúmeros contrassensos no seio das comunidades científicas que se debruçam sob o objeto. Contudo, o termo identificador em questão foi referendado como categoria abrangente para designar grupos cristãos missionários remanescentes do protestantismo. Cf. Mafra (2001).

${ }^{5}$ Vista pela OMS como uma prática terapêutica, o Reiki se baseia culturalmente na Índia pré-patriarcal, logo, é uma ramificação do budismo Qigong chinês, também sendo influenciado pelo Xintoísmo japonês. Desenvolve práticas de cura através da imposição de mãos, utiliza símbolos e espaços específicos, porém, segundo seguidores, não se trata de uma religião, mas de uma instituição ritualística. Isso gera discordância no seio teológico e da ciência da religião, fazendo com que pensadores enxerguem o Reiki como uma prática religiosa individual. Cf. Teixeira (2009).
} 


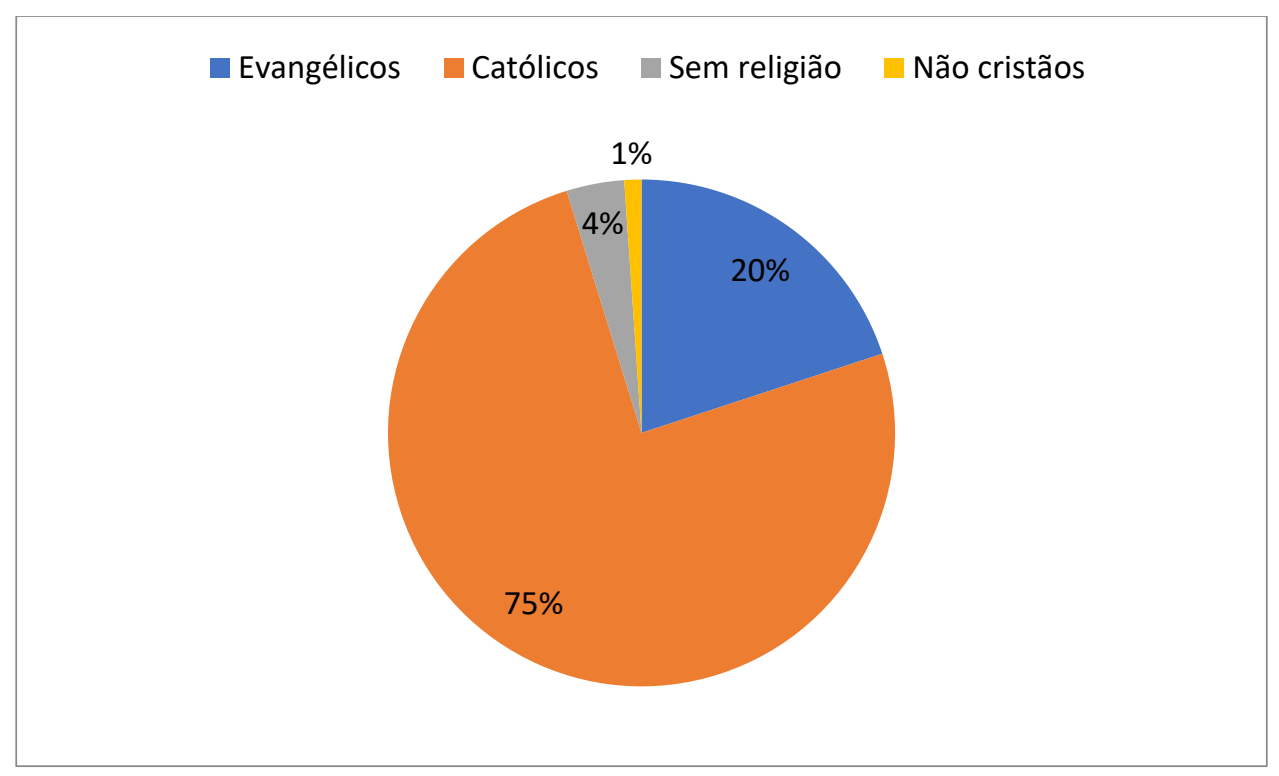

Figura 2 - Religiões da população residente em Juazeiro do Norte - CE em 2010. Fonte: Elaborado pelos autores com base na tabela 137 do SIDRA/IBGE relativa ao Censo Demográfico de 2010 do IBGE.

Comparando-se os dados do IBGE (2010) com os do IBGE (2000), conclui-se que houve uma redução de adeptos do catolicismo e ascensão de seguidores de outras doutrinas religiosas, especialmente evangélicas, em Juazeiro do Norte. Por ocasião do Censo Demográfico de 2000, a população católica dessa cidade correspondia a 88\%, enquanto a de evangélicos consistia em 11\%, a de sem religião, 1,083\% e a de não cristãos, 0,298\%. Logo, no Censo Demográfico de 2010 se constata uma redução de $13 \%$ no número de católicos, ao passo que há um crescimento de $9 \%$ no índice de evangélicos, além de uma ascensão de $2,917 \%$ no número de não religiosos e de $0,702 \%$ no valor de não cristãos. 0 município de Juazeiro do Norte, seguindo uma tendência nacional, vivencia um fenômeno de declínio do catolicismo, todavia, a sua hegemonia ainda é um fato na cidade.

Além da expressiva presença de templos e ramificações evangélicas em Juazeiro do Norte, tal como constatado por Diniz (2013), a cidade também porta, embora pouco representados nos dados oficiais, inúmeros terreiros de umbanda e candomblé. Nesse esteio, conforme evidencia Domingos (2011), em 2010, na RM Cariri havia 236 casas de umbanda e 14 de candomblé. Em Juazeiro do Norte, nesse mesmo ano, existiam 165 terreiros de umbanda e oito de candomblé, majoritariamente localizados em bairros urbano-periféricos.

Ainda no tocante à presença de terreiros de religiões de matrizes africanas e indígenas em Juazeiro do Norte, encontra-se em desenvolvimento uma pesquisa direcionada pelo Núcleo de Educação para a Promoção da Igualdade Racial (Nepir) que será disponibilizada, ao seu término, no sistema de vigilância socioassistencial da Secretaria Municipal de Desenvolvimento Social e Trabalho de Juazeiro do Norte - CE. Os dados parciais da investigação supracitada, relativos apenas a cinco dos 43 bairros da cidade, confirmam a existência de 36 casas religiosas no território, majoritariamente de umbanda (15 templos), das quais 34 se localizam em bairros urbano-periféricos e duas na zona rural (Nepir, 2020).

Consoante aos dados do Nepir (2020), no que se refere ao regime de propriedade dos locais onde se localizam os terreiros, 11 são imóveis próprios registrados em nome das lideranças religiosas, sete são imóveis próprios registrados em nome dos terreiros, seis são imóveis próprios registrados em nome de membros das organizações, oito são alugados e quatro apresentam outros regimes herdados ou cedidos por familiares. Dos terrenos próprios, três ainda não concluíram a quitação, ao 
passo que seis não responderam à questão. Sobre os tipos de documentações que os terrenos/imóveis possuem, apenas 11 detém escrituras legalmente reconhecidas.

Do total de templos religiosos até então mapeados pelo Nepir (2020), apenas quatro possuem personalidade jurídica. Contudo, 14 detêm certificados de utilidade pública (Federal, Estadual ou Municipal) - algo convergente ao fato de 16 dos terreiros desenvolverem ações e projetos socioculturais nas comunidades onde se localizam, fator que denota a essência da utilidade pública de tais organizações. Todavia, conforme a legislação municipal, dentre os anos de 2000 e 2020, a única casa religiosa de matriz africana com atestado de utilidade pública por parte do poder público municipal foi a organização não governamental Ilê Axé Omimdandereci e Mutalégi, reconhecida pela lei municipal no 3730 (Juazeiro do Norte, 2010). Nota-se que o baixo número de terreiros de religiões de matrizes africanas e indígenas com Cadastro Nacional da Pessoa Jurídica e com reconhecimento municipal de utilidade pública reflete diretamente nos processos de solicitação de doações públicas, considerando-se que estas exigem tal registro para a sua consolidação.

Com base no exposto, seriam essas religiões não hegemônicas detentoras de recursos materiais que as desinteressam galgar benesses da municipalidade de Juazeiro do Norte - CE? Ou, vivencia-se um contexto em que, historicamente, religiões cristãs - especialmente a Católica - detêm recursos e influências capazes de proporcionar-lhes júbilos em relação ao poder público, em detrimento de outras religiões? Indutivamente, não se possuem indicadores suficientes para responder tal indagação, porém, aspectos históricos e contemporâneos de hegemonia católica, a constatação de que a Igreja Católica foi a maior detentora das doações aqui observadas, a ausência de informações publicizadas sobre as doações solicitadas, bem como o considerável valor de terreiros de religiões de matrizes africanas e indígenas sem escrituras legalmente reconhecidas, sediados em imóveis alugados ou cedidos e os casos dos imóveis/terrenos próprios ainda sem quitação sinalizam para o fato de vivermos em um contexto público no qual elementos privados - como a religião - ainda assumem papéis direcionadores e que, intensamente, ferem a laicidade do Estado Brasileiro por edificarem assimetrias concretas entre distintas religiões.

Cabe-se esclarecer que as doações estudadas na presente pesquisa não se destinam exclusivamente à construção de templos religiosos, mas abarcam múltiplas finalidades. Dessa maneira, os possíveis interesses das instituições religiosas presentes na cidade poderiam contemplar a construção de centros de sociabilidade, sedes de projetos sociais/filantrópicos, espaços culturais de fomento à memória social religiosa, etc. Enfim, a ausência de doações de terrenos públicos a religiões não cristãs - excetuando-se uma organização reikiana - permite vislumbrar uma dualidade possível de fenômenos sociais: 1) desinteresse de religiões não hegemônicas em relação às doações; 2) dificuldades técnicas, jurídicas, políticas e culturais de religiões não hegemônicas no que tange ao acesso ao poder público. As duas hipóteses são possíveis e, certamente, coexistem, considerando-se que se direcionam a variadas ramificações e instituições religiosas, logo, plurais e impossíveis de terem os seus interesses e realidades homogeneizadas.

Embora apresentem naturezas religiosas, distintas foram as destinações das doações próprias da municipalidade, assim como se observa na Tabela 5. Cerca de $40 \%$ se destinaram à construção de templos católicos, ao passo que 10\% foram direcionadas à edificação de templos evangélicos. Cabe-se denotar que outras destinações também foram alvo das doações, contemplando desde a construção de sedes de organizações com fins religiosos a de entidades com fins filantrópicos/sociais. Salienta-se que a Constituição da República Federativa do Brasil (1988), em seu Art. 19, preconiza a viabilidade da cooperação entre instituições religiosas para com a União, estados, municípios e DF com vistas ao interesse público (Brasil, 1988), o que se projeta claramente nas doações próprias da municipalidade de Juazeiro do Norte para a construção de sedes de organizações religiosas que desenvolvem trabalhos filantrópicos/assistencialistas no território. Todavia, o volume massivo de doações para a construção de templos religiosos - católicos e evangélicos, bem como a não aplicação disso em relação a outras vertentes religiosas, fazem-nos questionar a propriedade laica de tais atos legislativos. 
Tabela 5 - Finalidades das doações a organizações/instituições religiosas

\begin{tabular}{lll}
\hline Finalidades das doações & N de doações & Percentual de doações (\%) \\
\hline Construções de templos católicos & 8 & $40 \%$ \\
Construções de templos evangélicos & 2 & $10 \%$ \\
Doações à lgreja Católica para outros fins & 2 & $10 \%$ \\
Construção de sedes de organizações & 8 & $40 \%$ \\
\hline Total & 20 & $100 \%$ \\
\hline
\end{tabular}

Fonte: Produzido pelos autores com dados da pesquisa.

O fato é confluente ao advogado por Mariano (2011) ao exclamar que, mesmo em um contexto democrático brasileiro, quando grupos laicos e laicistas lutam arduamente em prol dos direitos humanos, sexuais, reprodutivos e sociais, há uma intensa contracorrente gerada por setores religiosos cristãos - leia-se: católicos e evangélicos - que trabalham intensamente na busca pela ocupação do espaço público e consequente influência religiosa e axiológica nas políticas, bens e serviços públicos. Algo comprometedor do "mundo comum" idealizado por Arendt (2007), em que a pluralidade e liberdade ganham papel angular.

Santos (2002) propõe a sociologia das ausências, a qual afirma que as não existências são produtos intencionais, logo, deve-se buscar migrar os objetos entendidos como impossíveis para lugares possíveis, algo que contribuirá para a transformação das ausências - experiências tornadas opacas pela hegemonia metonímica - em presenças. Assim, Santos (2002) afirma que são variadas as formas de não existência, considerando-se a diversidade de caminhos através dos quais a razão metonímica atua na desqualificação, invisibilização e ininteligibilidade de dadas entidades. Dentre tais formas de produção de ausências, assenta-se a monocultura da naturalização das diferenças, consistindo em uma lógica classificatória dos sujeitos atuante na categorização desses, objetivando a naturalização das desigualdades sociais. Nesse sentido, a discriminação racial, sexual e a intolerância religiosa figuram como exemplos nítidos da monocultura da naturalização das diferenças.

Nesse raciocínio, ao contemplar a ausência de doações próprias da municipalidade para religiões não cristãs - excetuando-se uma doação para uma entidade reikiana nos 19 anos analisados —; o baixo número de organizações religiosas não cristãs com personalidade jurídica; a existência expressiva de templos de religiões de matrizes africanas e indígenas na cidade, o fato de diversos terreiros desempenharem projetos socioculturais (algo que exige recursos e espaços adequados), assim como as suas realidades materiais que apresentam demandas tocantes aos terrenos/imóveis onde se sediam (baixo número de propriedades com escrituras legalizadas, considerável valor de imóveis alugados ou cedidos por terceiros/lideranças religiosas/fiéis, expressivo número de imóveis próprios não quitados, ínfimo número de terreiros com personalidade jurídica), vislumbra-se à luz da sociologia das ausências um fenômeno em que a não existência de doações públicas a dadas vertentes religiosas implica uma realidade pública politicamente imbricada de desfavorecimento de doutrinas não cristãs nessa modalidade de doações municipais.

Enfim, como se nota na Figura 3, as doações efetivadas foram, majoritariamente, de áreas localizadas em bairros periféricos, com infraestrutura deficitária e consideravelmente distantes do centro da cidade. Grifa-se que a única doação de terreno público central foi feita à Diocese de Crato CE. Logo, as localidades com maior incidência de doações foram os bairros Frei Damião (15\%) e Campo Alegre (15\%), sequenciados pelos bairros Vila Fátima (10\%) e Tiradentes (10\%). Todos os demais portam $5 \%$ das doações (equivalente a 1 doação). 


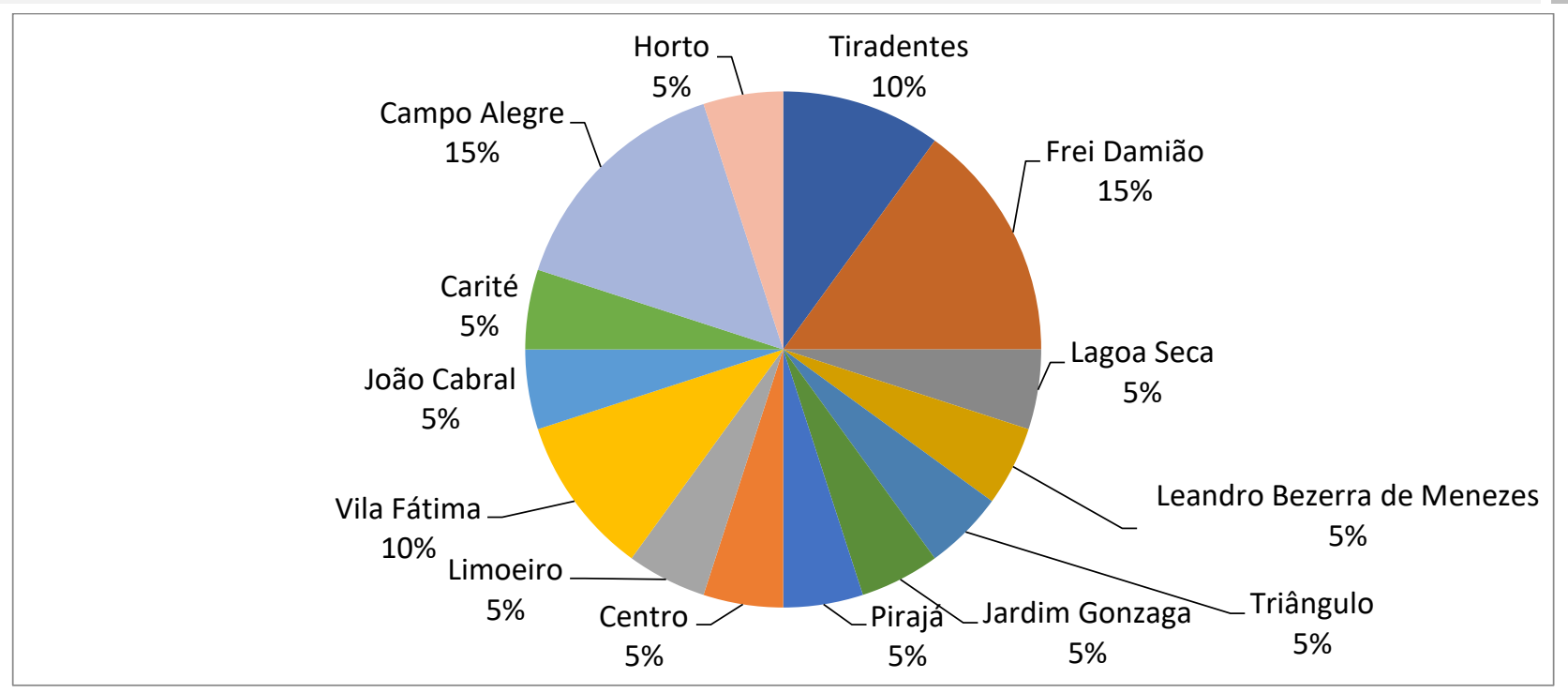

Figura 3 - Doações de terrenos por bairros do município de Juazeiro do Norte - CE. Fonte: Produzido pelos autores com dados da pesquisa.

Tal distribuição geográfica se justifica pelo trabalho social/filantrópico desenvolvido por algumas das organizações concedidas - levando-as para localidades com densos problemas socioambientais, mas também pelo trabalho essencialmente religioso que é praticado pela maioria das instituições contempladas com as doações - o que se aplica nas ações contemporâneas de "evangelização" de áreas "subdesenvolvidas". Esse fato é problemático, pois vislumbra-se uma conjuntura em que valores e princípios de cunho privado - religioso - fazem uso de bens públicos para a sua perpetuação, o que dificulta enxergar a sua utilidade pública tocante à função social da cidade. Escancara-se, assim, a crise da secularização alegada por Santos (2013), em que a separação do Estado e religiões se confronta com o recrudescimento do fundamentalismo religioso, crises democráticas e liberais - intrínsecas à secularização —, aumento da adesão religiosa por grupos outrora "secularizados" etc.

\section{Considerações Finais}

Constata-se que, mesmo em um contexto democrático em que a laicidade ocupa um espaço salutar nas prerrogativas constitucionais, os melindres entre as esferas pública e privada se agravam em virtude da presença de dadas ideologias religiosas no âmbito público. Isso converge às assimetrias tocantes às representações religiosas no espaço público, considerando-se que, historicamente, religiões cristãs protagonizam lobbys e influenciam nas deliberações políticas nacionais.

Nesse viés, destaca-se a grande parcela de doações próprias da municipalidade de Juazeiro do Norte a organizações/instituições/finalidades católicas e, em sobreposição, evangélicas. Esse fato não se projeta a religiões socialmente marginalizadas, tais como as de matrizes africanas, afro-brasileiras, espíritas e indígenas, numa realidade incongruente às prerrogativas constitucionais brasileiras, sobretudo, em virtude dos seus fins meramente religiosos e não equitativos em relação a doutrinas não cristãs e não hegemônicas.

A escassez de direcionamentos legais harmônicos às demandas atuais de Juazeiro do Norte esbarra na ausência de políticas públicas de planejamento e desenvolvimento urbano para a cidade de médio porte em voga. Nesse sentido, a obsolescência do Plano Diretor, bem como a fragilidade das pastas e interesses públicos em relação ao tema urbano e ambiental, faz com que patrimônios públicos (terrenos públicos) sejam doados sem critérios claros e objetivos, comprometendo o alcance da função social preconizada pela Constituição Federal de 1988. É algo nitidamente constatado quando se vislumbram doações públicas de terrenos para organizações/finalidades privadas. Não obstante, a concentração das 
doações a instituições cristãs (sobretudo católicas) desnuda o privilégio dessas doutrinas à revelia de organizações religiosas não hegemônicas. Portanto, nota-se a necessidade de melhor definição legal sobre os procedimentos e critérios para a consolidação das doações públicas na cidade.

Indica-se que, ao decorrer da pesquisa, constatou-se que nos anos pesquisados organizações beneficiadas com as doações públicas receberam reconhecimento legislativo municipal em relação à alegada utilidade pública dos seus trabalhos. Nesse direcionamento, dentre todos os entes contemplados com os atos legislativos, oito tiveram a sua utilidade pública reconhecida pelo poder público municipal. Destaca-se que, dentre tais organizações, seis são católicas, uma evangélica e uma reikiana. Considerando o total de entes com o reconhecimento municipal, três (cristãos católicos e evangélicos) gozaram das doações públicas efetivadas de modo anterior às publicações das leis atestantes da utilidade pública: Fundação Terra, Associação de Apoio aos Necessitados e Igreja Evangélica Assembleia de Deus.

Todavia, em conteúdos de textos legais de tais atos, apresentam-se justificativas meramente religiosas. Apenas três organizações concedidas com o título de utilidade pública apresentam objetivos e naturezas condizentes à defesa e promoção de direitos, bens e serviços fundamentais (Associação Comunitária do bairro Campo Alegre, Associação dos Reikianos do Cariri e Associação Maria Mãe da Vida); as cinco restantes são límpidas em suas configurações e anseios estritamente religiosos (Fundação Terra, Associação Mãe da Santíssima Trindade, Associação de Apoio aos Necessitados, Associação Jesus é o Senhor e a Imaculada Nossa Mãe, Igreja Evangélica Assembleia de Deus), algo que se nota mediante a presença das expressões linguísticas "acolhimento espiritual", "socialização humana e religiosa", "de caráter religioso", entre outras presentes nos textos legais de reconhecimento da utilidade pública de tais entidades.

Esse fato norteará a continuidade e aprofundamento da presente investigação, buscando, $a$ posteriori, entrevistar os parlamentares da Câmara de Vereadores de Juazeiro do Norte envolvidos nas ações sobre as razões das doações efetivadas e verificar in loco o andamento das construções ou o estado da ocupação dos terrenos públicos doados.

\section{Referências}

Antunes, M. A. (2004). O público e o privado em Hannah Arendt. Covilhã: Universidade da Beira Interior.

Arendt, H. (2007). A condição humana (10a ed.). Rio de Janeiro: Forense.

Brasil. (1988, 5 de outubro). Constituição da República Federativa do Brasil. Brasília: Senado Federal.

Brasil. (2011, 18 de novembro). Lei $n^{\circ} 12.527$, de 18 de novembro de 2011. Regula o acesso a informações previsto no inciso XXXIII do art. 5ำ, no inciso II do $§ 3^{\circ}$ do art. 37 e no $§ 2^{\circ}$ do art. 216 da Constituição Federal; altera a Lei n⿳0 8.112, de 11 de dezembro de 1990; revoga a Lei no 11.111, de 5 de maio de 2005, e dispositivos da Lei no 8.159, de 8 de janeiro de 1991; e dá outras providências. Brasília: Diário Oficial da União, seção 1.

Chueca, E. G. (2019). 0 direito à cidade perante as epistemologias do Sul: reflexões sobre o processo brasileiro de construção do direito à cidade. In Santos, B. de S., \& Martins, B. S. (Orgs.), o pluralismo dos Direitos Humanos: a diversidade das lutas pela dignidade (p. 397-418). Belo Horizonte: Autêntica Editora.

Cordeiro, M. P. J. (2010). Entre Chegadas e Partidas: Dinâmicas das Romarias em Juazeiro do Norte (Tese de Doutorado). Programa de Pós-Graduação em Sociologia, Universidade Federal do Ceará, Fortaleza.

Corrêa, R. L. (1989). O espaço urbano. São Paulo: Ática. Série Princípios.

Diniz, P. R. J. (2013). A construção do conceito de identidade a partir da análise realizada na Igreja do Evangelho Quadrangular, em Juazeiro do Norte. Revista Ciências da Religião-História e Sociedade, 11(2), 115-137. Recuperado em 14 de janeiro de 2020, de http://editorarevistas.mackenzie.br/index.php/cr/article/view/6445

Domingos, R. F. (2011). Pedagogias da transmissão da religiosidade africana na casa de candomblé Iabasé de Xangô e Oxum em Juazeiro do Norte-CE (Dissertação de Mestrado). Faculdade de Educação, Universidade Federal do Ceará, Fortaleza, CE, Brasil. 
Gil, A. C. (2008). Métodos e técnicas de pesquisa social (6ª ed.). São Paulo: Editora Atlas.

Giumbelli, E. (2008). A presença do religioso no espaço público: modalidades no Brasil. Religião \& Sociedade, 28(2), 80101. https://dx.doi.org/10.1590/S0100-85872008000200005

Grostein, M. D. (2001). Metrópole e expansão urbana: a persistência de processos "insustentáveis". São Paulo em perspectiva, 15(1), 13-19. https://dx.doi.org/10.1590/S0102-88392001000100003

Holanda, S. B. de. (1995). Raízes do Brasil. São Paulo: Companhia das Letras.

Instituto Brasileiro de Geografia e Estatística - IBGE. (2000). Censo de 2000. Recuperado em 20 de julho de 2020, de https://sidra.ibge.gov.br/Tabela/1969

Instituto Brasileiro de Geografia e Estatística - IBGE. (2010). Censo de 2010. Recuperado em 13 de março de 2020, de http://www.censo2010.ibge.gov.br/

Juazeiro do Norte (2000, 8 de setembro). Lei $n^{\circ}$ 2.572, de 08 de setembro de 2000. Dispõe sobre o Plano Diretor de Desenvolvimento Urbano, PDDU de Juazeiro do Norte e dá outras providências. Juazeiro do Norte: Diário oficial do município.

Juazeiro do Norte (2010, 24 de agosto). Lei no 3730, de 24 de agosto de 2010. Reconhece de utilidade pública a ONG Ilê Axé Omimdandereci e Mutalégi e adota outras providências. Juazeiro do Norte: Diário oficial do município.

Karnal, L. (2017). Todos contra todos: o ódio nosso de cada dia. Rio de Janeiro: Leya.

Lefebvre, H. (1972). O pensamento marxista e a cidade (Maria Idalina Furtado, Trad.). Lisboa: Editora Ulisseia.

Lühning, A. (1996). Acabe com esse santo, Pedrito vem aí: Mito e realidade da perseguição policial ao candomblé baiano entre 1920 e 1942. Revista Usp, (28), 194-220. https://doi.org/10.11606/issn.2316-9036.v0i28p194-220.

Mafra, C. (2001). Os evangélicos (1ª ed.). Rio de Janeiro: Zahar.

Mariano, R. (2011). Laicidade à brasileira. Católicos, pentecostais e laicos em disputa na esfera pública. Civitas - Revista de Ciências Sociais, 11(2), 238-258. http://dx.doi.org/10.15448/1984-7289.2011.2.9647

Maricato, E. (2015). Para entender a crise urbana. CaderNAU, 8(1), 11-22. Recuperado em 25 de fevereiro de 2010, de https://periodicos.furg.br/cnau/article/viewFile/5518/3425

Morettin, L. G. (2010). Estatística Básica: Probabilidade e Inferência. São Paulo: Pearson Prentice Hall.

Núcleo de Educação e Promoção para Igualdade Racial - Nepir (2020, julho 20). Solicitação de Informações [correspondência eletrônica].

Oliveira, P. W. A. de. (2019). Ser-tão romeiro: a memória hierofânica do catolicismo popular sertanejo e sua espacialização em Juazeiro do Norte-CE (Tese de doutorado). Instituto de Estudos Socioambientais, Universidade Federal de Goiás, Goiânia, GO, Brasil.

Prodanov, C. C., \& Freitas, E. C. (2013). Metodologia do trabalho científico: métodos e técnicas da pesquisa e do trabalho acadêmico (2a ed.). Novo Hamburgo: Feevale.

Rodrigues, A. (2019). Expansão populacional de Juazeiro gera debate sobre Plano Diretor. Diário do Nordeste. Recuperado em 18 de abril de 2020, de https://diariodonordeste.verdesmares.com.br/editorias/regiao/expansaopopulacional-de-juazeiro-gera-debate-sobre-plano-diretor-1.2182196

Santos, B. de S. (2002). Para uma sociologia das ausências e uma sociologia das emergências. Revista crítica de ciências sociais, (63), 237-280. https://doi.org/10.4000/rccs.1285

Santos, B. de S. (2013). Pela mão de Alice: o social e o político na pós-modernidade (14a ed.). São Paulo: Cortez.

Teixeira, N. B. (2009). Reiki: Religião ou prática terapêutica? HORIZONTE - Revista de Estudos de Teologia e Ciências da Religião, 7(15), 142-156. https://doi.org/10.5752/P.2175-5841.2009v7n15p142

\section{Editor responsável: Rodrigo Firmino}

Recebido em 11 mai. 2020

Aprovado em 22 set. 2020 